\title{
Spectroelectrochemical study of the oxidation of diaminophenols on platinum electrodes in acidic medium
}

\author{
H.J. Salavagione ${ }^{a}$, J. Arias-Pardilla ${ }^{\text {b }}$, J.L. Vázquez ${ }^{\text {b, }}$, M.C. Miras ${ }^{\text {a }}$, \\ E. Morallón ${ }^{\mathrm{b}, *, 1}$, C. Barbero ${ }^{\mathrm{a}, 1}$ \\ a Departamento de Química, Universidad Nacional de Río Cuarto, Agencia Postal No. 3, 5800 Río Cuarto, Argentina

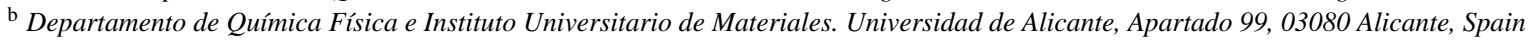

Received 10 December 2004; received in revised form 16 February 2005; accepted 4 March 2005

\begin{abstract}
The electrochemical oxidation of 2,3- 2,4- and 2,5-diaminophenol, on platinum electrode, in acid medium was studied using cyclic voltammetry, in situ UV-vis and in situ FTIR spectroscopies. The spectroscopic data indicates that 2,4-diaminophenol suffers hydrolysis giving the formation of 2-amino-hydroquinone/2-amino- $p$-benzoquinone in solution. The oxidation mechanism of 2,5-diaminophenol is similar to the $p$-phenylenediamine giving 2-hydroxy- $p$-benzoquinoneimine and its hydrolysis product, 2-hydroxy- $p$-benzoquinone. The electrochemical results suggest that 2,3-diaminophenol generates a non-electroactive polymeric material on the electrode surface.
\end{abstract}

(C) 2005 Elsevier Ltd. All rights reserved.

Keywords: Diaminophenol; In situ FTIR spectroscopy; Cyclic voltammetry; Platinum electrode; Oxidation

\section{Introduction}

Aminophenols have been extensively studied because, unlike aniline [1] and other substituted anilines [2], they have two groups $\left(-\mathrm{NH}_{2}\right.$ and $\left.-\mathrm{OH}\right)$, which could be oxidized. Therefore, they could show electrochemical behavior resembling anilines [1-3] and/or phenols [4,5]. In earlier works, we have studied the oxidation of the three isomers of aminophenols using in situ FTIR spectroscopy [6]. The $p$-aminophenol shows a cyclic voltammogram with a quasi-reversible redox couple without formation of polymeric product. The spectroscopic results indicate that oxidized $p$-aminophenol suffers hydrolysis giving the formation of hydroquinone/ $p$ benzoquinone in solution [6]. The electrochemical oxidation of $m$-aminophenol produces a yellow polymeric product on the platinum surface that inhibits the subsequent oxidation. The polymeric product could have a crosslinked [6] or a linear structure analogous to polyphenol [6,7]. On the other hand,

\footnotetext{
* Corresponding author. Tel.: +34 965909590; fax: +34 965903537 .

E-mail address: morallon@ua.es (E. Morallón).

1 ISE member.
}

the electrochemical oxidation of $o$-aminophenol produces electroactive dimmers, which polymerize to form an electroactive material on the electrode surface [6,8-11]. Poly $(o-$ aminophenol) (POAP) has been characterized [10,12-17], its electrochemical and electrochromic properties studied [9,18-24] and the material applied to sensors [25-33] and metal deposition [34].

The chemical and electrochemical oxidation of phenylenediamines has been extensively researched [35]. Chemical oxidation of $p$-phenylenediamines ( $p$-PD) and $N$-substituted derivatives has been extensively explored due to its application in hair coloring and color photography [36-40]. The electrochemical oxidation of $p$-PD in aqueous acidic medium produces $p$-benzoquinone as final product $[38,40]$. However, it has been reported that $p$-PD produces a polymeric powder by chemical oxidative polimerization $[35,41]$. The electro-oxidation of both $m$-phenylenediamine ( $m$-PD) and $o$-phenylenediamine (o-PD) produces polymeric films [35]. $m$-Phenylenediamine polymers could present two structures including rigid rod-like ladder or network type, depending on the coupling orientation in the $m$-PD monomer [35,42]. Both structures are electroinactive. Oyama et al. reported the elec- 
tropolymerization of $o$-phenylenediamine (o-PD) [43-45] to form an electroactive film. The poly $(o$-phenylenediamine (Po-PD) is a ladder polymer [46] with structure and properties closely related to those of poly $(o$-aminophenol) $[9,12]$. Barbero et al. reported that the global reaction rate of $o$-PD polymerization is faster than $o$-AP polimerization [12]. While the polymer produced by oxidation of $o$-PD in acid media is electroactive, the polymers produced in neutral or basic media are insulating [47].

Diaminophenols (DAP) are interesting compounds because they could be oxidized like aminophenols and/or phenylenediamines. The electro-oxidation of 2,3diaminophenol (2,3-DAP) has been investigated in few electrolytic media [48]. Polymeric (or olygomeric) deposits are obtained only when very anhydrous acetonitrile is used as solvent [48]. 2,4-Diaminophenol (2,4-DAP) hydrochloride salt (know as amidol) has been utilized as a developing agent in photography [49], since 1892 because is one of the few organic developing agents that remain active in a slightly acidic solution. However, 2,4-DAP properties has not been analyzed in detail. To our knowledge, electrochemical studies of 2,5diaminophenol (2,5-DAP) oxidation do not exist. Due to the intensive colors and good fastness properties, 2,5-DAP and other dyes known as oxidation colorants, play a prominent role in the coloring of keratin fibers, particularly human hair [50-54].

In this work we report the study of the oxidation of three isomers of diaminophenol on platinum electrodes in acidic medium, using cyclic voltammetry, in situ UV-vis and in situ FTIR spectroscopy. Using these techniques and molecular modelling, a dimerization mechanism for the three isomers is proposed.

\section{Experimental}

The test solutions were $1 \mathrm{M} \mathrm{HClO}_{4}$ prepared form Merck Suprapur concentrated acid. Diaminophenols were from Aldrich and used as received. All diaminophenols are stable as a dry chemical but deteriorates rapidly in aqueous solution. Therefore, all solutions were prepared before using and stored at low temperature and light protected. The water employed for the preparation of the solutions was obtained from an Elga Labwater Purelab Ultra system. $\mathrm{D}_{2} \mathrm{O}$ was from Aldrich chemicals, 99 at.\% D. A reversible hydrogen electrode (RHE) immersed in the same solution was used as reference electrode.

The polycrystalline platinum electrode was thermally cleaned and subsequently protected from the laboratory atmosphere by a droplet of ultrapure water. Then, it was transferred to the working solution (previously deaerated by bubbling $\mathrm{N}_{2}$ ) where it was immersed at controlled potential. The cyclic voltammograms were recorded at a constant sweep rate of $50 \mathrm{mV} \mathrm{s}^{-1}$, at room temperature. The counter electrode used for the experiments was a spiral of platinum foil.
A Nicolet Magna 850 spectrometer equipped with a liquid nitrogen-cooled MCT detector was employed for in situ FTIR measurements. The sample compartment was purged throughout the experiment using a 75-50 Balston clean air package. The electrode used was a polycrystalline platinum disc of $8 \mathrm{~mm}$ diameter obtained from Goodfellow Metals (purity $99.99 \%$ ). The disc was mounted on a glass tube and its surface was polished using alumina of several sizes $(1,0.3$ and $0.05 \mu \mathrm{m}$ ). A platinum electrode was used as counter electrode. The thin layer spectroelectrochemical cell was made of glass and was provided with a prismatic $\mathrm{CaF}_{2}$ windows bevelled to $60^{\circ}$. Spectra were collected at $8 \mathrm{~cm}^{-1}$ resolution and are presented as $\Delta R / R$.

For in situ UV-vis measurements an Avantes 2000 spectrometer equipped with a Avantes DH-2000 halogen and deuterium sources and an Avaspec 2048-2 detector was employed. The cell of $1-\mathrm{cm}$ optic length is a quartz cuvette connected to the lamps and detector trough two Avantes FC-UV050-2-SR optics fibers. For these measurements, the working electrode was a platinum disc $6 \mathrm{~mm}$ in diameter (to ensure the creation of a high concentration of species), the counter-electrode was a platinum foil and the reference electrode was a RHE immersed in a lugging containing $1 \mathrm{M}$ $\mathrm{HClO}_{4}$ solution. The working electrode was immersed in the cuvette at controlled potential and spectra were acquired with a 5-min delay from the step potential to avoid diffusional effects.

Molecular modeling of reactants and intermediates was performed with Hyperchem 5.0 using the semi-empirical self-consistent field method (AM1).

\section{Results and discussion}

\subsection{2,3-Diaminophenol oxidation}

Fig. 1 shows several cyclic voltammograms for a polycrystalline platinum electrode in $1 \mathrm{M} \mathrm{HClO}_{4}+1 \times 10^{-4} \mathrm{M}$

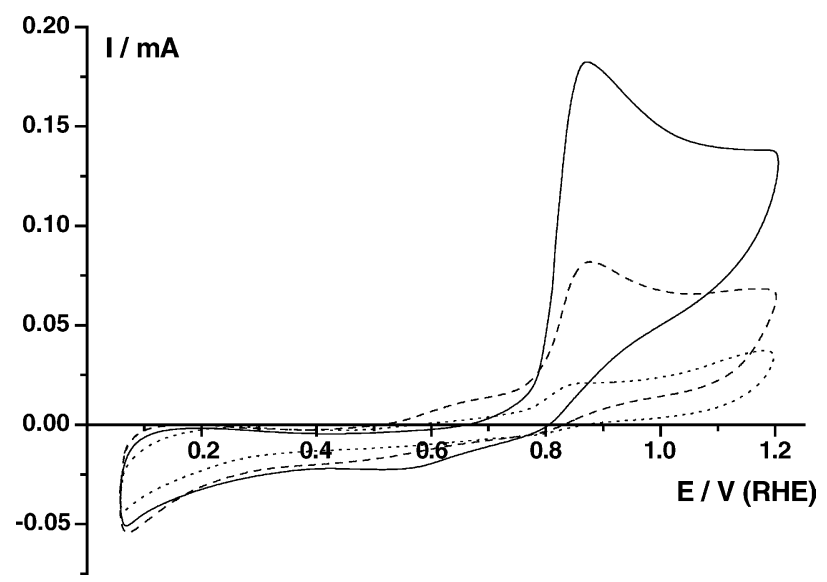

Fig. 1. Cyclic voltammograms for a Pt electrode immersed in $1 \mathrm{M}$ $\mathrm{HClO}_{4}+1 \times 10^{-4} \mathrm{M}$ 2,3-DAP solution, (-) first cycle, (-- -) seventh cycle and $(\cdots)$ 20th cycle, $v=50 \mathrm{mV} \mathrm{s}^{-1}$. 


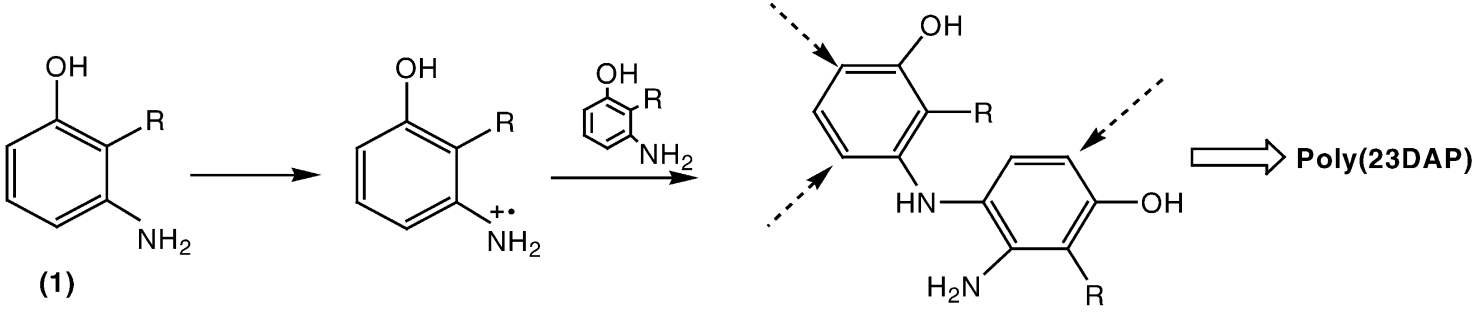

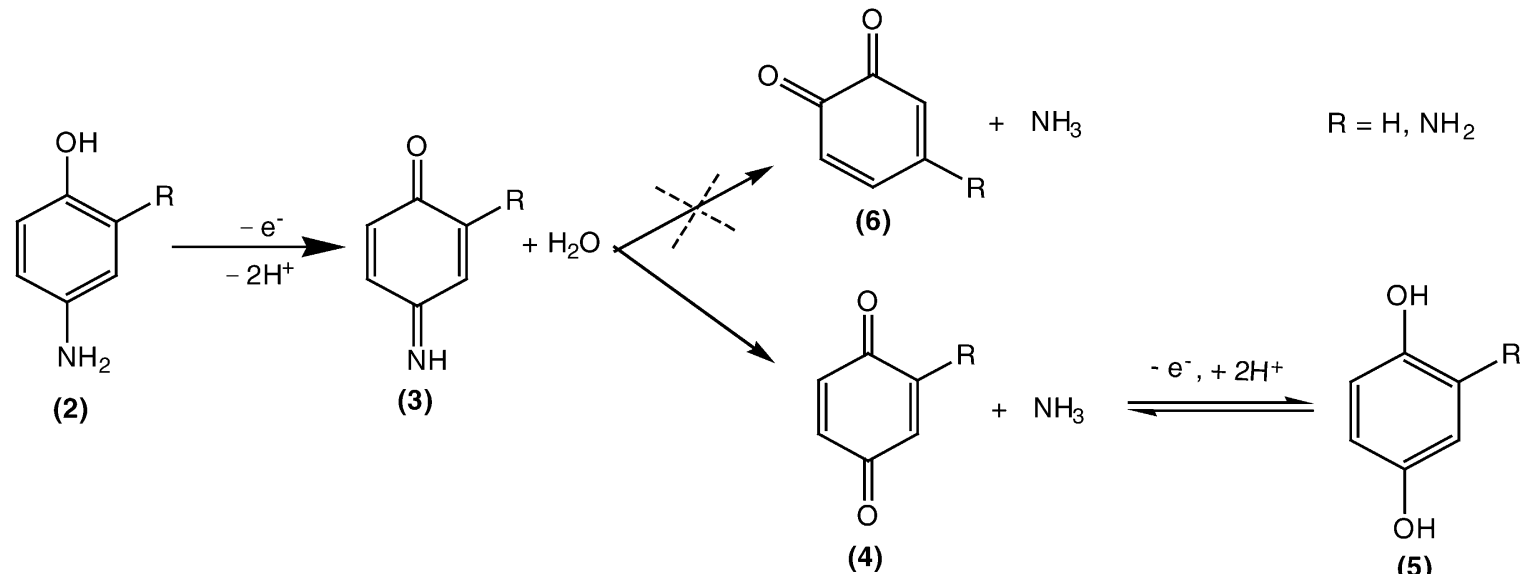<smiles>[R]c1cc(N)ccc1N</smiles>

(7)<smiles>[R]C1=CC(=N)C=CC1=N</smiles>

(8)<smiles>[R]C1=CC(=N)C=CC1=O</smiles>

(9)

$\mathrm{R}=\mathrm{H}, \mathrm{OH}$<smiles>[R]C1=CC(=N)C=CC1=O</smiles>

(10)

(11)<smiles>[R]C1=CC(=O)C=CC1=O</smiles>

(12)

Scheme 1.

2,3-DAP ((1) in Scheme 1) in the limit of 2,3-DAP solubility. The electrode is immersed at $0.2 \mathrm{~V}$ and the potential was swept to more positive values. The first cycle (Fig. 1, solid line) shows a broad anodic peak at $0.89 \mathrm{~V}$ without its corresponding reduction counterpart in the reverse scan, indicating a fast follow up chemical reaction. The next cycles show a lower oxidation current suggesting the formation of a blocking film on the electrode surface. After the 100th cycle, the electrode was removed from de solution and washed with ultrapure water and immersed in a $1 \mathrm{M} \mathrm{HClO}_{4}$ solution free of 2,3-DAP. Fig. 2 shows the voltammograms obtained under these conditions, in which the characteristic voltammetric profile for a thermally treated platinum electrode is not obtained (Fig. 2, dotted line). The adsoption-desorption pro- cesses that occur between 0.06 and $0.5 \mathrm{~V}$ are blocked and the current density associated with the surface oxidation at potentials higher than $0.6 \mathrm{~V}$ is smaller than those obtained for a thermally treated platinum electrode. This behavior confirms the formation of an electroinactive polymeric or olygomeric film on the electrode surface. In addition, the electrochemical response obtained for 2,3-DAP resembles to those obtained for $m$-aminophenol [6] in the same conditions, suggesting that the oxidation of 2,3-DAP could also produce a crosslinked or a polyphenol-like material (Scheme 1). However, 2,3-DAP could also be seen as a $o$-phenylenediamine derivative and $\mathrm{Po}-\mathrm{PD}$ is a ladder polymer with cyclic structure [46] like poly $(o$-aminophenol) $[9,12]$. Indeed, Del Valle et al. have proposed that poly(2,3-DAP), produced in dry acetonitrile, 


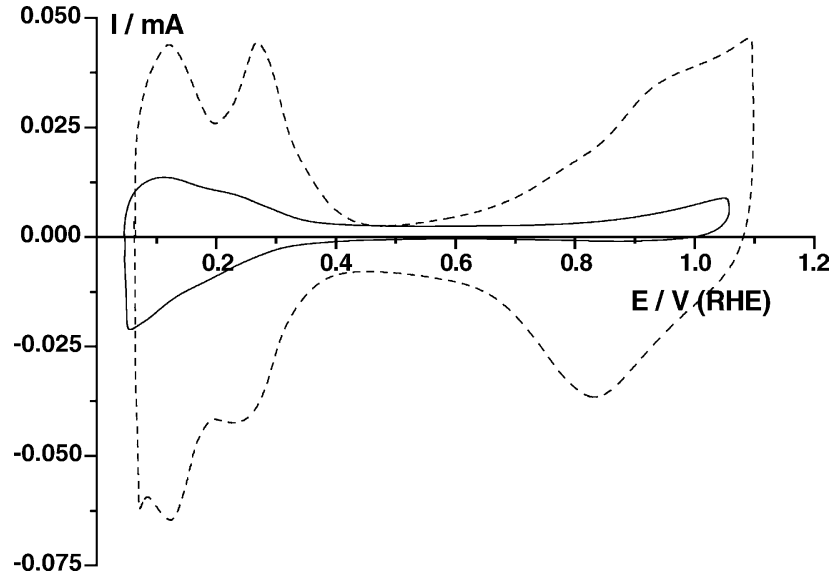

Fig. 2. (-) Steady state voltammogram for a Pt electrode covered by poly(2,3-DAP) in $1 \mathrm{M} \mathrm{HClO}_{4}$ solution after hundredth cycles in $1 \mathrm{M}$ $\mathrm{HClO}_{4}+1 \times 10^{-4} \mathrm{M} 2,3$-DAP solution. (---) Steady voltammogram for a thermally treated Pt electrode in $1 \mathrm{M} \mathrm{HClO}_{4}$ solution, $v=50 \mathrm{mV} \mathrm{s}^{-1}$.

has a ladder structure similar to Po-PD, with the hydroxyl group linked to the ladder backbone [48].

In order to clarify the structure of poly(2,3-DAP) it is necessary to know the mechanism of 2,3-DAP dimerization or polymerization. For this purpose, we analyzed the species produced during the 2,3-DAP oxidation using in situ FTIR spectroscopy. Fig. 3 shows the FTIR spectra obtained for a polycrystalline platinum electrode in a $1 \mathrm{M}$ $\mathrm{HClO}_{4}+1 \times 10^{-4} \mathrm{M}$ 2,3-DAP solution. The working electrode is introduced into the solution at $0.2 \mathrm{~V}$ and the reference spectrum (100 interferograms) was collected. The potential was then stepped to higher values taken 100 interferograms
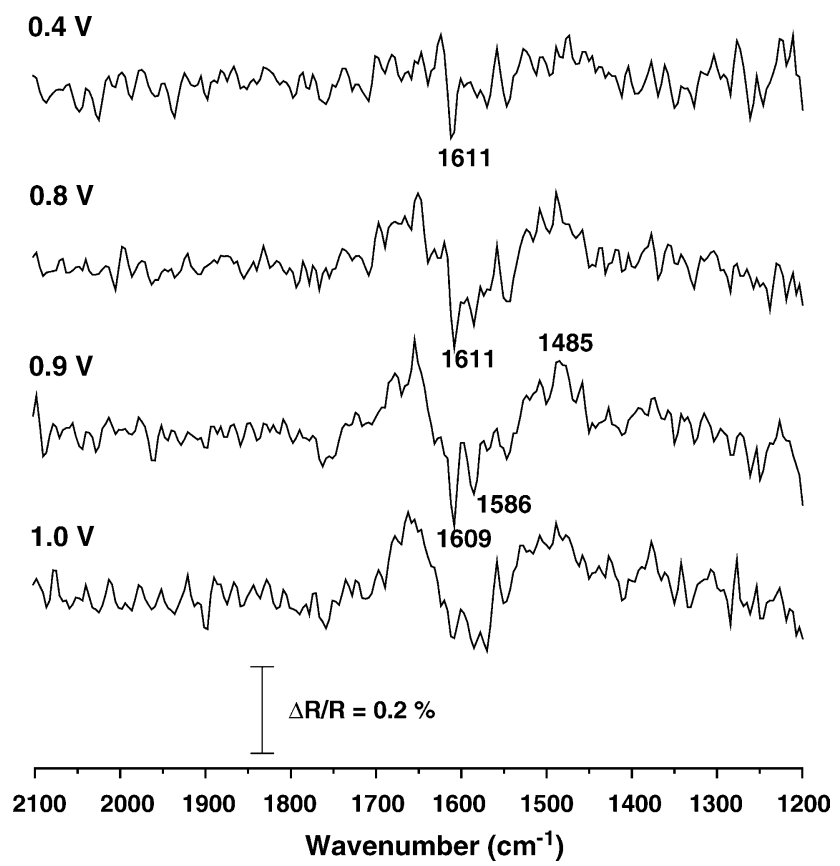

Fig. 3. FTIR spectra at different potentials for a Pt electrode in a $1 \mathrm{M}$ $\mathrm{HClO}_{4}+1 \times 10^{-4} \mathrm{M}$ 2,3-DAP. Reference potential: $0.2 \mathrm{~V}$. Hundred interferograms at each spectrum. at each step. When the potential increases a positive band at $1485 \mathrm{~cm}^{-1}$ appears in the spectra, which can be attributed to the $\mathrm{C}=\mathrm{C}$ stretching vibration of the aromatic ring. The positive character of this band suggests that the aromatic ring is disappearing as 2,3-DAP its oxidized. Two negative bands at 1586 and $1609 \mathrm{~cm}^{-1}$ are also observed when the potential increases. These bands could be assigned to the $\mathrm{C}=\mathrm{N}$ stretching vibration. Several attempts have been performed in order to obtain better spectra changing the solvent to deuterated water without success.

The electronic density distribution of 2,3-DAP and its dimer obtained using the semi-empirical self-consistent field method (AM1) are shown in Fig. 4. 2,3-DAP has a high electronic density in the para position with respect to the $-\mathrm{OH}$ group (Fig. 4 (a)). Then, dimers could be produced through the attack of the cation radical at that position (Scheme 1). Both $\mathrm{N}$ atoms in the monomer have more electronic density than the $\mathrm{O}$ atom. Therefore, it is easier to withdraw an electron of the nitrogen atoms leading to the formation of an $\mathrm{N}$-linked dimer (Fig. 4(b)). The resulting dimers have three positions with similar electronic densities, favoring multiple addition of cation radicals to the dimer.

In summary, data obtained by cyclic voltammetry and molecular modeling support the formation of a branched insulating polymer when 2,3-DAP is oxidized in $\mathrm{HClO}_{4} 1 \mathrm{M}$ on a platinum electrode.

\subsection{2,4-Diaminophenol oxidation}

Fig. 5 shows the steady state voltammogram obtained for a polycrystalline platinum electrode in $1 \mathrm{M}$ $\mathrm{HClO}_{4}+1 \times 10^{-3} \mathrm{M}$ 2,4-DAP ((2) in Scheme 1) solution. The voltammogram shows an anodic peak at $0.85 \mathrm{~V}$ with its corresponding reduction counterpart in the reverse scan at $0.52 \mathrm{~V}$. This profile is maintained when the electrode is cycled between 0.06 and $1.2 \mathrm{~V}$ from the first cycle suggesting a quasi-reversible electrochemical reaction in solution without the formation of a solid deposit on the electrode surface. This behavior is similar to those observed for the oxidation of $p$-aminophenol and hydroquinone under the same conditions [6,55], however the redox processes is less reversible in this case. Thus, this profile indicates that 2,4DAP suffers hydrolysis giving the formation of substituted hydroquinone (5)/substituted $p$-benzoquinone (4) redox couple in solution like $p$-aminophenol oxidation (Scheme 1). Furthermore, a similar electrochemical response is also obtained on glassy carbon (GC) electrodes. Although, in this case, the voltammogram shows a slightly more irreversible behaviour (figure not shown) than in the case of platinum electrode.

In order to identify the species produced during the 2,4DAP oxidation, in situ FTIR spectroscopy was performed. The FTIR spectra obtained for a polycrystalline platinum electrode in a $1 \mathrm{M} \mathrm{HClO}_{4}+1 \times 10^{-3} \mathrm{M} 2,4$-DAP deuterated water solution is shown in Fig. 6(a). After the flame treatment, the platinum electrode was introduced in the working 

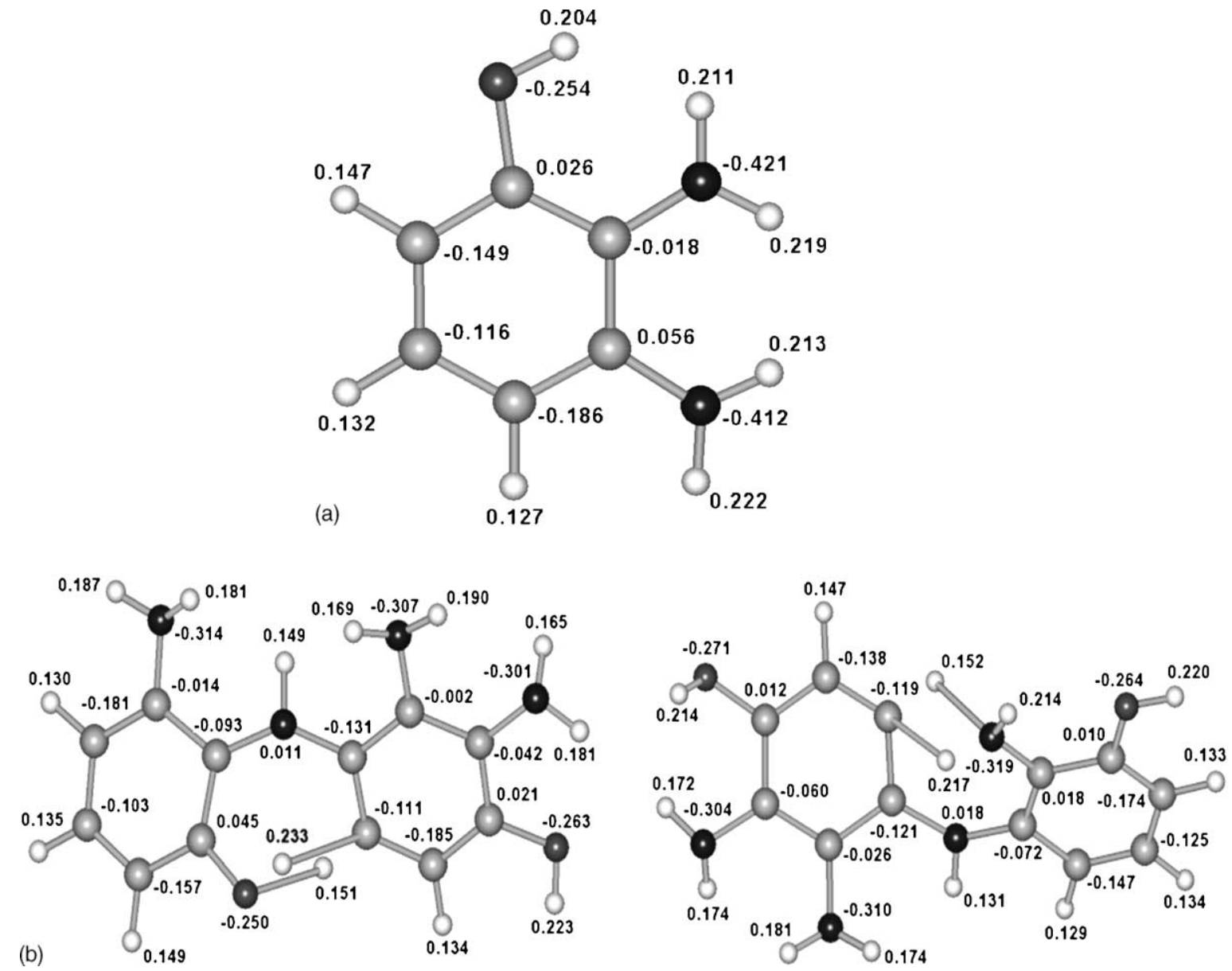

Fig. 4. Electronic density calculations for 2,3-DAP (a) obtained using the semi-empirical self-consistent method (AM1), together with the head-to-tail (N-linked) dimmer (b).

solution at $0.2 \mathrm{~V}$ and the reference spectrum (100 interferograms) was acquired. The potential was then polarized at higher values and the sample spectrum (100 interferograms) was taken. When the potential reaches a value of $0.8 \mathrm{~V}$, two positive bands at 1461 and $1528 \mathrm{~cm}^{-1}$ appear, which can be associated to the aromatic $\mathrm{C}=\mathrm{C}$ stretching vibration. The

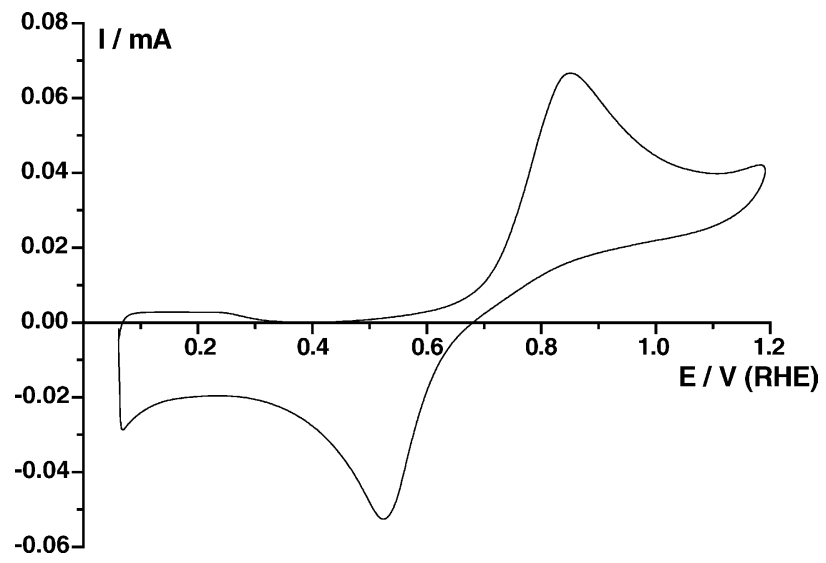

Fig. 5. Steady state voltammogram for a Pt electrode immersed in $1 \mathrm{M}$ $\mathrm{HClO}_{4}+1 \times 10^{-3} \mathrm{M} 2,4$-DAP solution, $v=50 \mathrm{mV} \mathrm{s}^{-1}$. first one can be assigned to the $\mathrm{C}=\mathrm{C}$ stretching of $1,2,4$ trisubstituted benzenes [56], while the band at $1528 \mathrm{~cm}^{-1}$ corresponds to the $\mathrm{C}=\mathrm{C}$ stretching that appears in the oxidation of aminophenols [6]. The positive character of these bands indicates that these groups are disappearing during the oxidation of 2,4-DAP. Nonetheless, three negative bands at 1565,1602 and $1646 \mathrm{~cm}^{-1}$ is observed during the 2,4-DAP oxidation. Furthermore, when the potential is polarized at $1 \mathrm{~V}$ an additional band a $1693 \mathrm{~cm}^{-1}$ emerges (Fig. 6(a)). The bands at 1565 and $1602 \mathrm{~cm}^{-1}$ can be due to $\mathrm{C}=\mathrm{N}$ stretching vibration of quinoneimine species [57]. It is known that paraquinones may present either one or two bands due to carbonyl stretching [56]. Thus, the bands at 1646 and $1693 \mathrm{~cm}^{-1}$ can be assigned to the $\mathrm{C}=\mathrm{O}$ stretching vibration of the 2-amino$p$-benzoquinone ((4) with $\left.\mathrm{R}=\mathrm{NH}_{2}\right)$. However, the possibility that 4-amino-o-benzoquinone $\left(6\right.$ with $\mathrm{R}=\mathrm{NH}_{2}$ ) are also generated during the oxidation of 2,4-DAP cannot be discarded. However, ortho-quinones [56] display only one carbonyl band around $1660 \mathrm{~cm}^{-1}$ [56]. So, at lower potentials, 4-amino-o-benzoquinone (6) are the only generated species and when the potential is polarized over $1 \mathrm{~V}$ a mixture of 4amino-o-benzoquinone (6) and 2-amino- $p$-benzoquinone (4) is produced. 


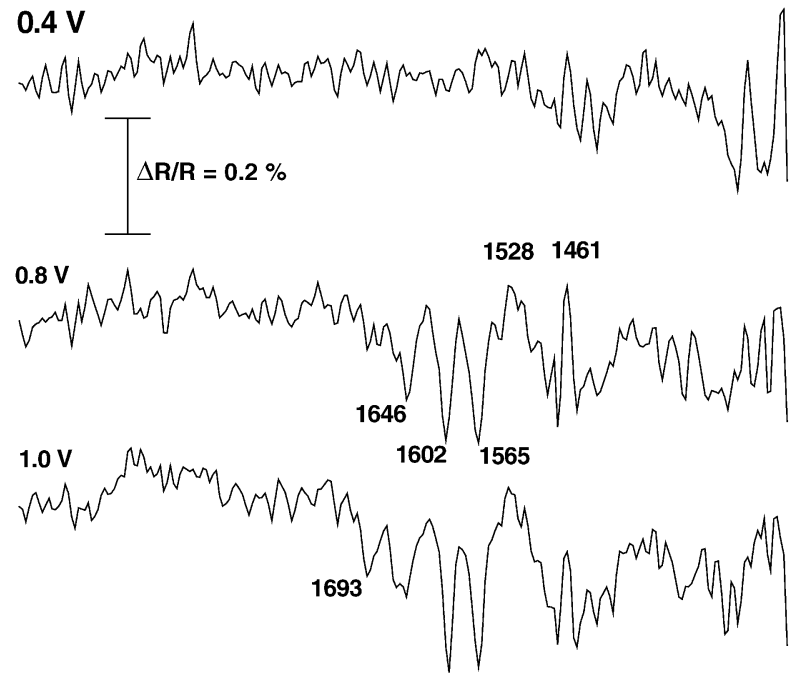

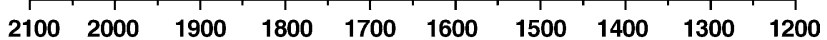

(a)
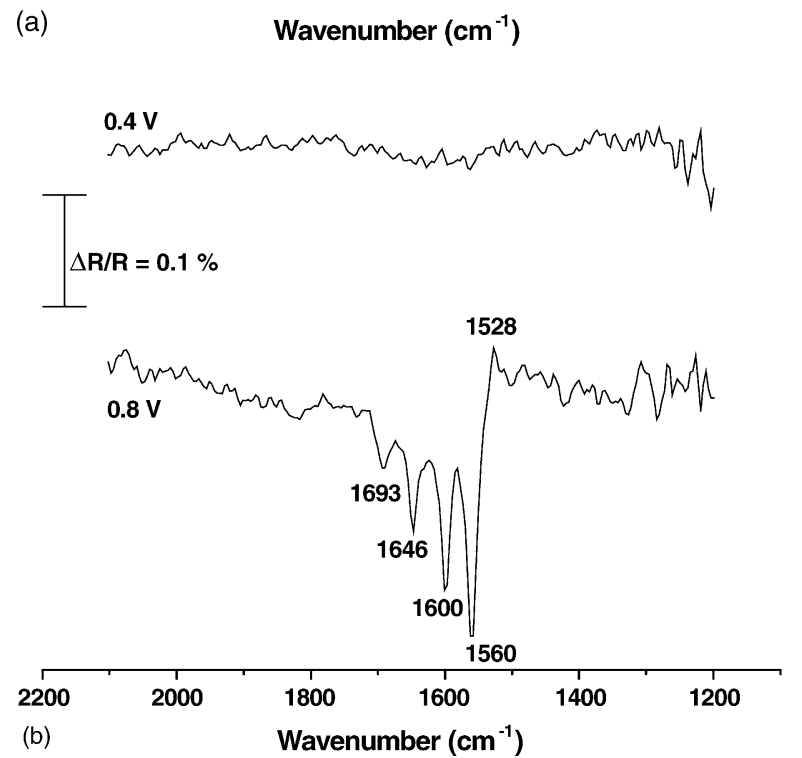

Fig. 6. (a) FTIR spectra at different potentials for a Pt electrode in a $1 \mathrm{M}$ $\mathrm{HClO}_{4}+1 \times 10^{-3} \mathrm{M}$ 2,4-DAP in deuterated water solution, 100 interferograms at each spectrum. (b) SNIFTIR spectra of the same conditions of (a), 1000 interferograms. Reference potential: $0.2 \mathrm{~V}$.

SNIFTIRS (substractivelly normalized interfacial Fourier transforms infrared spectroscopy) experiment was carried out in the same conditions. This technique is useful because it allows to accumulate interferograms between both reference and sample potential and then, increase the signal/noise ratio. Fig. 6(b) shows the SNIFTIR spectra during 2,4-DAP oxidation, taken in the same conditions than Fig. 6(a) (reference potential was $0.2 \mathrm{~V}$ ). It can be observed two bands at 1646 and $1693 \mathrm{~cm}^{-1}$ at $0.8 \mathrm{~V}$ (at the beginning of the redox peak), that can be assigned to the stretching of the $>\mathrm{C}=\mathrm{O}$ group. Consequently, 2-amino- $p$-benzoquinone (4) should be the predominant product of 2,4-DAP oxidation (Scheme 1).

The oxidation of 2,4-DAP was also examined using in situ UV measurements. Fig. 7 shows the change of the electronic

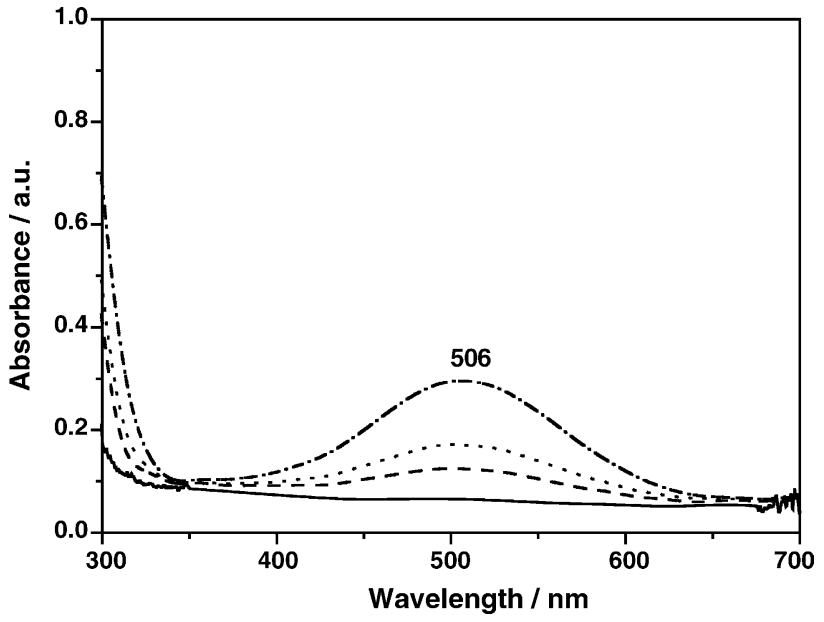

Fig. 7. UV-vis spectra at different potential in a $1 \times 10^{-3} \mathrm{M} 2,4-\mathrm{DAP}$ in $1 \mathrm{M} \mathrm{HClO}_{4}$ solution. Sample potential (-) $0.2 \mathrm{~V},(--) 0.5 \mathrm{~V},(\cdots) 1.0$ and $(-\cdot-\cdot-\cdot) 1.2 \mathrm{~V}$.

spectra of $1 \mathrm{M} \mathrm{HClO}_{4}+1 \times 10^{-3} \mathrm{M}$ 2,4-DAP solution. The working electrode was immersed in the cuvette at $0.1 \mathrm{~V}$, and the potential was then polarized at higher values and the sample spectrum was taken. A new band around $506 \mathrm{~nm}$ appears when the potential increased. A similar band between 460 and $480 \mathrm{~nm}$ was observed when $p$-aminophenol is oxidized [58].

In summary, 2,4-DAP suffers hydrolysis giving the formation of 2-amino-hydroquinone (5)/2-amino- $p$-benzoquinone (4) redox couple in solution.

\subsection{2,5-Diaminophenol oxidation}

Fig. 8 shows the voltammograms obtained for a polycrystalline platinum electrode in $1 \mathrm{M} \mathrm{HClO}_{4}+1 \times 10^{-3} \mathrm{M} 2,5$ DAP ((7) in Scheme 1) solution. The first cycle (solid line) shows an anodic peak at $0.98 \mathrm{~V}$ with its corresponding re-

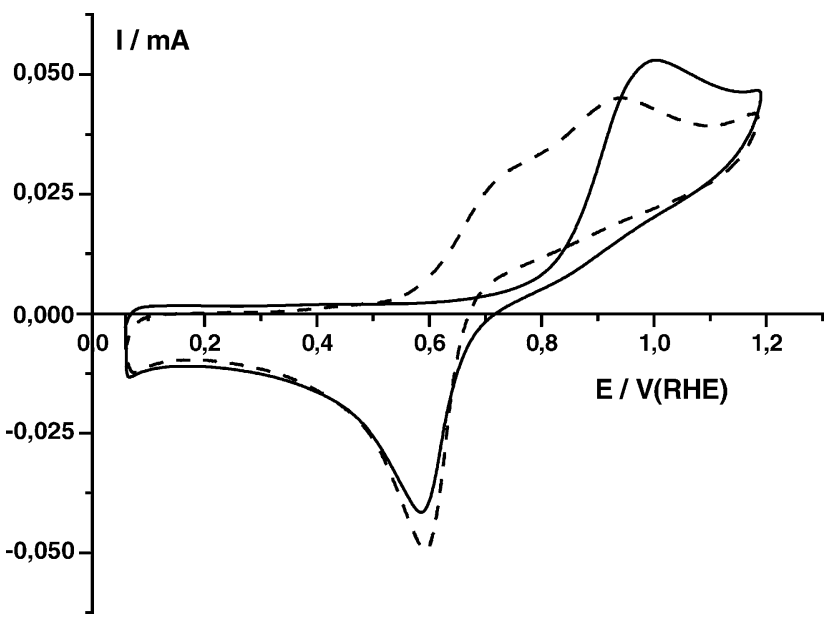

Fig. 8. Cyclic voltammograms for a $\mathrm{Pt}$ electrode immersed in $1 \mathrm{M}$ $\mathrm{HClO}_{4}+1 \times 10^{-3} \mathrm{M} 2,5$-DAP solution, (-) first cycle and (-- ) second cycle, $v=50 \mathrm{mV} \mathrm{s}^{-1}$. 
duction counterpart in the reverse scan around $0.6 \mathrm{~V}$. In the next cycle (dashed line) a new anodic peak around $0.75 \mathrm{~V}$ appears, however, during the cathodic scan only the peak at $0.6 \mathrm{~V}$ is observed. Continuous cycling of the electrode between 0.06 and $1.2 \mathrm{~V}$ does not alter the profile obtained during the second cycle. However, the peak at $0.75 \mathrm{~V}$ disappear when the solution is gently stirred by $\mathrm{N}_{2}$ bubbling (figure not shown) which suggest that the species responsible of this peak is a soluble product which is not reduced in the reverse sweep to lower potentials. Furthermore, on glassy carbon electrodes the oxidation of 2,5-DAP shows a similar behaviour that those observed in platinum electrode. In the first cycle, the oxidation peak appears around $1 \mathrm{~V}$, while the reduction one appear at $0.55 \mathrm{~V}$ (figure not shown). In addition, a shoulder at $0.66 \mathrm{~V}$ is observed in the second oxidation scan. However, in glassy carbon electrodes both, oxidation and reduction peak, are broad and less defined than in the case of platinum electrodes.

Again, to study the oxidation of 2,5-DAP in acidic medium in situ FTIR was employed. Fig. 9(a) shows the FTIR spectra obtained for a polycrystalline platinum electrode in a $1 \mathrm{M}$ $\mathrm{HClO}_{4}+1 \times 10^{-3} \mathrm{M} 2$,5-DAP deuterated water solution. At $0.8 \mathrm{~V}$, the spectrum shows negative bands at 1579,1640 and $1656 \mathrm{~cm}^{-1}$ whose intensities increase with the potential until $1 \mathrm{~V}$. Thus, at $1 \mathrm{~V}$, three clearly negative bands at 1579,1655 and $1690 \mathrm{~cm}^{-1}$ appear. The two first one may be assigned to the $\mathrm{C}=\mathrm{N}$ stretching vibration quinoneimine species and the latter one to the $\mathrm{C}=\mathrm{O}$ stretching vibration of quinone species. The negative character of these bands indicates that these species are produced as a consequence of the oxidation of 2,5-DAP. Furthermore, a positive band at $1505 \mathrm{~cm}^{-1}$ can be observed at $1 \mathrm{~V}$ which can be assigned to the aromatic ring $\mathrm{C}=\mathrm{C}$ stretching vibration that disappears when the potential increases.

SNIFTIRS experiments were performed in the same conditions. Fig. 9(b) shows the SNIFTIR spectra of 2,5-DAP oxidation in $1 \mathrm{M} \mathrm{HClO}_{4}$ deuterated water solution. At $0.8 \mathrm{~V}$ four negative bands at $1579,1634,1656$ and $1690 \mathrm{~cm}^{-1}$ can be perceived. The band at $1634 \mathrm{~cm}^{-1}$ could be assigned to $\mathrm{C}=\mathrm{N}$ stretching vibration of quinoneimine groups which intensity decreases when the potential increases, however, the intensity of the band at $1656 \mathrm{~cm}^{-1}$ increases with the potential. The band at $1690 \mathrm{~cm}^{-1}$ assigned to $\mathrm{C}=\mathrm{O}$ stretching vibration of quinoid ring is observed at all potentials. Then, the band at $1634 \mathrm{~cm}^{-1}$ corresponds to 2hydroxy-p-benzoquinonediimine $((\mathbf{8})$ with $\mathrm{R}=\mathrm{OH})$ that is produced in the first oxidation peak and after its hydrolysis produces 2-hydroxy- $p$-benzoquinone ((12), with $\mathrm{R}=\mathrm{OH}$, in Scheme 1).

On other hand, when the potential is stepped at $1.2 \mathrm{~V}$ (see Fig. 9(a) and (b)) a negative band at $1720 \mathrm{~cm}^{-1}$ is clearly observed and the bands commented above corresponding to quinone and quinoneimine species disappeared. This band corresponds to $\mathrm{C}=\mathrm{O}$ stretching vibration of carboxylic acids, which are produced by the breaking of the aromatic ring.

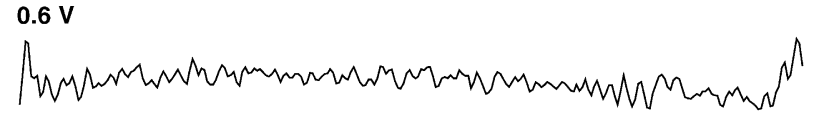

$0.8 \mathrm{~V}$

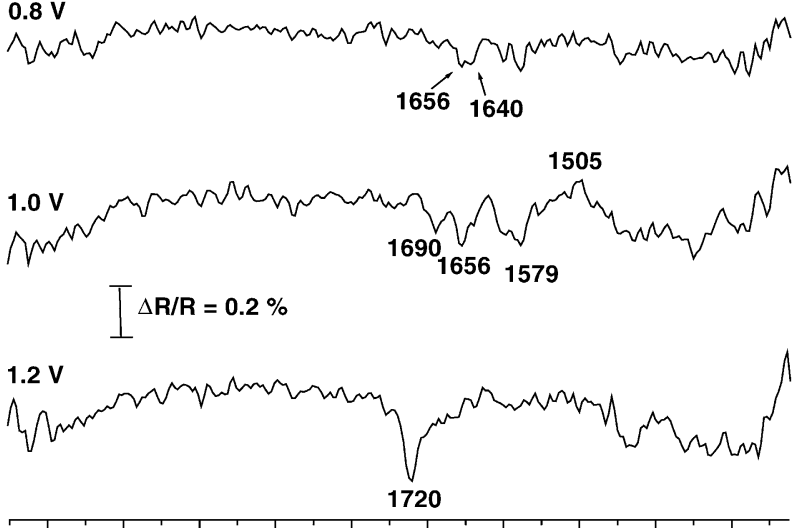

$\begin{array}{llllllllll}2200 & 2100 & 2000 & 1900 & 1800 & 1700 & 1600 & 1500 & 1400 & 1300\end{array}$

(a)

Wavenumber $\left(\mathrm{cm}^{-1}\right)$
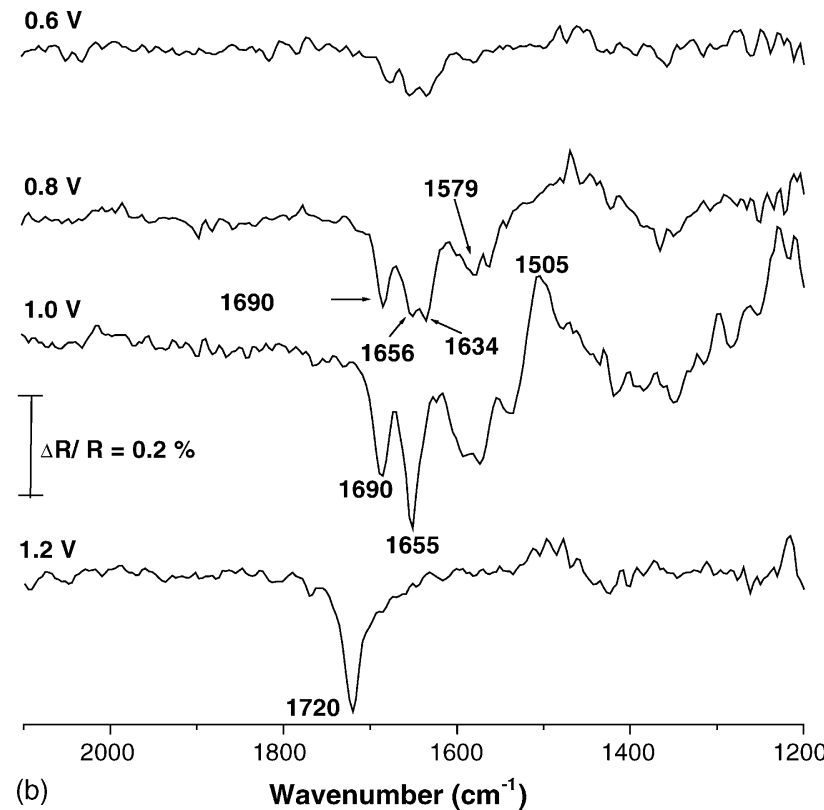

Fig. 9. (a) FTIR spectra at different potentials for a Pt electrode in a $1 \mathrm{M}$ $\mathrm{HClO}_{4}+1 \times 0^{-3} \mathrm{M}$ 2,5-DAP in deuterated water solution, 100 interferograms at each spectrum. (b) SNIFTIR spectra of the same conditions of (a), 1000 interferograms. Reference potential: $0.2 \mathrm{~V}$.

The oxidation of 2,5-DAP was also examined using in situ UV measurements. Fig. 10 shows the change of the electronic spectra of $1 \mathrm{M} \mathrm{HClO}_{4}+1 \times 10^{-3} \mathrm{M} 2,5$-DAP solution. The experiment was carried out in the same condition that those utilized for 2,4-DAP. In this case, as the potential is increased, a new band at $417 \mathrm{~nm}$ is developed. It is known that the hydroxy-p-quinones present a band between 350 and $435 \mathrm{~nm}$ [59].

In summary, the voltammetric and spectroelectrochemical data suggest that 2,5-DAP oxidation produces in its first 


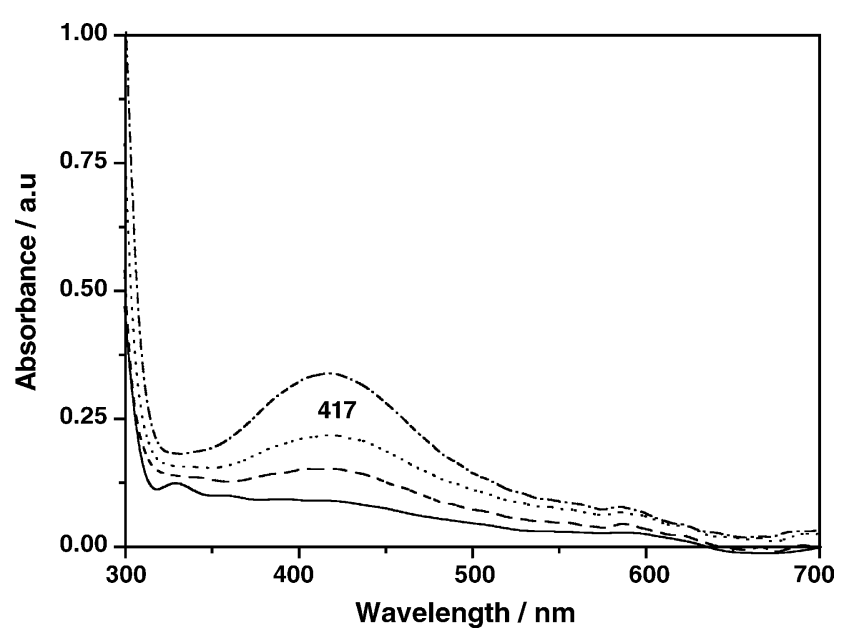

Fig. 10. UV-vis spectra at different potentials in a $1 \times 10^{-3} \mathrm{M} 2,5$-DAP in $1 \mathrm{M} \mathrm{HClO}_{4}$ solution. Sample potential (-) $0.2 \mathrm{~V},(---) 0.5 \mathrm{~V},(\cdots) 1.0 \mathrm{y}$ $(\cdot \cdots \cdot) 1.2 \mathrm{~V}$.

oxidation step quinones species that are oxidized to higher potential values.

\section{Conclusions}

The electrochemical oxidation of 2,3- 2,4- and 2,5diaminophenol has been investigated by means of cyclic voltammetry and in situ UV-vis and FITR spectroscopy. The electrochemical behavior of the three DAP isomers in acidic medium on platinum electrodes are very different.

The comparative mechanism of diaminophenol oxidation is described in Scheme 1. There are remarkable differences in the oxidation mechanism of the three DAP isomers. Only the oxidation of 2,3-DAP give rises to a non-electroactive polymeric film on the electrode surface. Its dimers have three positions with similar electronic densities (Fig. 4(b)), leading to multiple addition of cation radicals to the dimer. Therefore, the resulting material will have a crosslinked structure.

The oxidation of 2,4-DAP shows a cyclic voltammograms with a quasi-reversible redox couple without formation of polymeric films on the electrode, this behaviour is similar to that obtained with $p$-aminophenol. The spectroscopy information suggests that 2,4-DAP suffer hydrolysis giving the formation of 2-amino-hydroquinone (5)/2-amino- $p$ benzoquinone (4) redox couple in solution. In this compound the para-position with respect to the $-\mathrm{OH}$ group is blocked; thus the cation radical could not couple with the monomer free trough head to tail electrophillic substitution. The amino group in position 2 does not have an effect in the oxidation and behave like an inert group. Therefore, the preferred pathway is the formation of 2-amino-p-benzoquinone (4).

The electrochemical oxidation of 2,5-DAP shows a cyclic voltammograms with a quasi-reversible redox process preceded by a first oxidation peak without formation of solid deposit on the electrode surface. The first oxidation peak, that disappears when the solution is gently stirred, could be due to the formation of 2-hydroxy- $p$-benzoquinoneidiimine (8) in solution. 2-Hydroxy-p-benzoquinone (12) may be obtained by the oxidation of 2,5-DAP because those behave as $p$-phenylenediamine. When 2,5-DAP is oxidized, 2-hydroxy-p-benzoquinonediimine (8) is generated at lower potentials, which could be hydrolyzed to 2hydroxy-p-benzoquinoneimine (9) and subsequently to 2hydroxy- $p$-benzoquinone (12). Furthermore, 2-hydroxy- $p$ benzoquinoneimine (9) could be reduced to produce a 2,4DAP-type compound (2-hydroxy- $p$-aminophenol (10), with $\mathrm{R}=\mathrm{OH}$ ), which also generates 2-hydroxy- $p$-benzoquinone (12) when is oxidized.

\section{Acknowledgments}

Financial supports by the Ministerio de Educación y Ciencia (MAT2004-1479), as well as CONICET, FONCYT, Agencia Cordoba Ciencia and SECyT-UNRC are gratefully acknowledged. C. Barbero is a permanent research fellow of CONICET. Financing of the collaboration between Universidad de Alicante and UNRC by Fundación Antorchas is also gratefully acknowledged. H.J.Salavagione thanks ADEMATNetwork (ALFA-UE) for the financing of an Advanced Training stay at U. Alicante.

\section{References}

[1] H. Yang, A.J. Bard, J. Electroanal. Chem. 339 (1992) 423.

[2] N. Yamada, K. Teshima, N. Kobayashi, R. Hirohashi, J. Electroanal. Chem. 394 (1995) 71.

[3] J. Chiang, A.G. MacDiarmid, Synth. Met. 13 (1986) 193.

[4] M. Gattrell, D.W. Kirk, J. Electrochem. Soc. 139 (1992) 2736.

[5] R. Lapuente, F. Cases, P. Garces, E. Morallón, J.L. Vázquez, J. Electroanal. Chem. 451 (1998) 163.

[6] H.J. Salavagione, J. Arias, P. Garcés, E. Morallón, C. Barbero, J.L. Vázquez, J. Electroanal. Chem. 565 (2004) 375.

[7] O.I. Konopelnik, O.I. Aksimentyeva, M.Y. Grytsiv, Mater. Sci. 20 (2002) 49.

[8] C. Barbero, J. Zerbino, L. Sereno, D. Posadas, Electrochim. Acta 32 (1987) 341.

[9] T. Ohsaka, S. Kunimura, N. Oyama, Electrochim. Acta 33 (1988) 639.

[10] A. Guenbour, A. Kacemi, A. Benbachir, L. Aries, Prog. Org. Coat. 38 (2000) 121.

[11] D. Gonçalves, R.C. Faria, M. Yonashiro, M.-O.S. Bulhões, J. Electroanal. Chem. 487 (2000) 90.

[12] C. Barbero, J.J. Silber, L. Sereno, J. Electroanal. Chem. 263 (1989) 333.

[13] S. Kunimura, T. Oshaka, N. Oyama, Macromolecules 21 (1988) 894.

[14] Y. Yang, Z. Lin, Synth. Met. 78 (1996) 111.

[15] R. Tucceri, J. Electroanal. Chem. 562 (2004) 173.

[16] F. Gobal, K. Malek, M.G. Mahjani, M. Jafarian, V. Safarnavadeh, Synth. Met. 108 (2000) 15.

[17] H.J. Salavagione, J. Arias-Pardilla, J.M. Pérez, J.L. Vázquez, E. Morallón, M.C. Miras, C. Barbero, J. Electroanal. Chem. 567 (2005) 139.

[18] C. Barbero, R.I. Tucceri, D. Posadas, J.J. Silber, L. Sereno, Electrochim. Acta 40 (1995) 1037.

[19] F.J. Rodríguez Nieto, D. Posadas, R.I. Tucceri, J. Electroanal. Chem. 434 (1997) 83. 
[20] R.I. Tucceri, C. Barbero, J.J. Silber, L. Sereno, D. Posadas, Electrochim. Acta 42 (1997) 919.

[21] A.Q. Zhang, C.Q. Cui, Y.Z. Chen, J.Y. Lee, J. Electroanal. Chem. 373 (1994) 115.

[22] T. Komura, Y. Ito, T. Yamaguti, K. Takahasi, Electrochim. Acta 43 (1998) 723.

[23] J.M. Ortega, Thin Solid Film 371 (2000) 28.

[24] R.I. Tucceri, J. Electroanal. Chem. 505 (2001) 72.

[25] M.A. Valdes Garcia, P. Tuñon Blanco, A. Ivaska, Electrochim. Acta 43 (1998) 3533.

[26] M.J. Lobo, A.J. Miranda, J.M. López-Fonseca, P. Tuñon, Anal. Chim. Acta 325 (1996) 33

[27] J. Yano, H. Kawakami, S. Yamasaki, Synth. Met. 102 (1999) 1335.

[28] J.M. Ortega, Thin Solid Films 360 (2000) 159.

[29] A.Q. Zhang, C.Q. Cui, J.Y. Lee, J. Electroanal. Chem. 413 (1990) 143.

[30] J. Yano, H. Kawakami, S. Yamasaki, Y. Kanno, J. Electrochem. Soc. 148 (2001) 61.

[31] S.M. Golabi, A. Nozad, Electroanalysis 15 (2003) 278.

[32] D. Pan, J. Chen, L. Nie, W. Tao, S. Yao, Electrochim. Acta 4 (2004) 795.

[33] M.C. Miras, A. Badano, M.M. Bruno, C. Barbero, Portugaliae Electrochim. Acta 21 (2003) 235.

[34] N. Hernández, J.M. Ortega, M. Choy, R. Ortiz, J. Electroanal. Chem. 515 (2000) 123.

[35] X.-G. Li, M.-R. Huang, W. Duan, Chem. Rev. 102 (2002) 2925 (and references therein).

[36] L.F. Fieser, J. Am. Chem. Soc. 52 (1930) 4915.

[37] L. Michaelis, E.S. Hill, J. Am. Chem. Soc. 55 (1933) 1481.

[38] L.K.J. Tong, M.C. Glesmann, R.L. Bent, J. Am. Chem. Soc. 82 (1960) 1988.

[39] L.K.J. Tong, R.C. Baetzold, J. Am. Chem. Soc. 93 (1971) 1347.

[40] L.K. Tong, J. Phys. Chem. 58 (1954) 1090.

[41] B. Rawat, S.S. Kansara, H.S. Rama, Polym. Int. 26 (1991) 233.
[42] X.-G. Li, W. Duan, M.-R. Huang, Y.-L. Yang, D.-Y. Zhao, Q.-Z. Dong, Polymer 44 (2003) 5579.

[43] Y. Ohmuki, H. Matsuda, T. Ohsada, N.J. Oyama, J. Electroanal. Chem. 158 (1983) 55.

[44] K. Chiba, T. Ohsada, N.J. Oyama, J. Electroanal. Chem. 217 (1987) 239.

[45] N.J. Oyama, T. Ohsada, Synth. Met. 18 (1987) 375.

[46] K. Chiba, T. Ohsaka, Y. Ohnuki, N.J. Oyama, J. Electroanal. Chem. 219 (1987) 117.

[47] I. Losito, F. Palmisano, P.G. Zambonin, Anal. Chem. 75 (2003) 4988 (and references therein).

[48] M.A. Del Valle, E.T. Silva, F.R. Diaz, M.E. Bodini, L. Gargallo, J. Polym. Sci. A: Polym. Chem. 38 (2000) 1698.

[49] M.D. Purol, P.A. Zielinski, D.L. Kerr, Eur. Pat. Appl. EP 565,459, 1993.

[50] H. Moeller, D. Oberkobusch, H. Hoeffkes, Eur. Pat. Appl. EP $1,300,132,2003$.

[51] W. Gross, D. Oberkobusch, H. Hoeffkes, Eur. Pat. Appl. EP 1,300,134, 2003.

[52] D. Rose, H. Hoeffkes, B. Meinigke, US Patent 20,030,037,386 (2003).

[53] D. Rose, H. Hoeffkes, B. Meinigke, US Patent 20,030,041,393 (2003).

[54] D. Rose, H. Hoeffkes, B. Meinigke, US Patent 20,030,106,167 (2003).

[55] Z. Wang, X. Li, Y. Wu, Y. Tang, Sh. Ma, J. Electroanal. Chem. 464 (1999) 181.

[56] G. Socrates, Infrared an Raman Characteristics Frequencies of Organic Molecules, third ed., Wiley, New York, 2001.

[57] Y. Furukawa, T. Hara, Y. Hyodo, I. Harada, Synth. Met. 16 (1986) 189.

[58] J. Schwarz, W. Oelßner, H. Kaden, F. Schumer, H. Hennig, Electrochim. Acta 48 (2003) 2479.

[59] D.J. Pasto, C.R. Johnson, Organic Structure Determination, PrenticeHall, Englewood Cliff, NJ, 1974. 